\title{
Mesodinium rubrum exhibits genus-level but not species-level cryptophyte prey selection
}

\author{
Elina Peltomaa ${ }^{1, *}$, Matthew D. Johnson ${ }^{2, *, * *}$ \\ ${ }^{1}$ Department of Environmental Sciences, University of Helsinki, Helsinki 00014, Finland \\ ${ }^{2}$ Department of Biology, Woods Hole Oceanographic Institution, Woods Hole, MA 02543, USA
}

\begin{abstract}
The marine ciliate Mesodinium rubrum is known to form large non-toxic red water blooms in estuarine and coastal upwelling regions worldwide. This ciliate relies predominantly upon photosynthesis by using plastids and other organelles it acquires from cryptophyte prey. Although M. rubrum is capable of ingesting different species of cryptophytes, mainly Teleaulax amphioxeia plastids have been detected from wild $M$. rubrum populations. These observations suggest that either $M$. rubrum is a selective feeder, or $T$. amphioxeia are taken up because of higher availability. To test these hypotheses, we determined whether the ciliate showed different grazing rates, growth responses, or plastid retention dynamics when offered Storeatula major, $T$. amphioxeia, $T$. acuta, or a mix. When $M$. rubrum was offered the cryptophyte $S$. major as prey, no evidence was found for ingestion. In contrast, M. rubrum grazed both Teleaulax spp. equally, was able to easily switch plastid type between them, and the ratio of each in the ciliate reflected the abundance of free-living prey in the culture. M. rubrum grew equally well when acclimated to each plastid type or when having mixed plastids. However, when offered single prey, $T$. amphioxeia could sustain higher $M$. rubrum growth rates $(\mu)$ over longer periods. Compared to other M. rubrum strains, this culture had higher grazing rates, greater ingestion requirements for reaching $\mu_{\max }$ and appeared to rely more on plastid sequestration than de novo division of cryptophyte organelles. Our results suggest that while M. rubrum may prefer Teleaulax-like cryptophytes, they do not select among the species used here.
\end{abstract}

KEY WORDS: Mixotrophy · Acquired phototrophy $\cdot$ Kleptoplastidy · Grazing · Prey selection · Species-specific qPCR $\cdot$ Mesodinium $\cdot$ Teleaulax

\section{INTRODUCTION}

The marine ciliate Mesodinium rubrum Lohmann, 1908 (= Myrionecta rubra Jankowski, 1976) can form massive non-toxic red blooms in estuaries and coastal upwelling regions worldwide (Lindholm 1985). M. rubrum is an obligate mixotroph that relies primarily upon phototrophy and preys on cryptophytes in order to sequester plastids and other organelles (Yih et al. 2004, Johnson \& Stoecker 2005, Johnson et al. 2006, Smith \& Hansen 2007, Hansen et al. 2012). M. rubrum is unusual for its ability to sequester a functional cryptophyte nucleus, which it uses to control and replicate its plastids (Johnson et

\footnotetext{
* The authors contributed equally to this work

${ }^{* *}$ Corresponding author: mattjohnson@whoi.edu
}

al. 2007, Lasek-Nesselquist et al. 2015). This elaborate prey-handling mechanism raises questions about the extent to which $M$. rubrum's acquired photosynthetic potential depends upon the ingestion of specific prey species. In addition, M. rubrum-like ciliates are now known to be a species complex composed of at least 8 distinct subclades (Herfort et al. 2011, Garcia-Cuetos et al. 2012, Johnson et al. 2016). One of these clades has been officially described as a new species, M. major (Garcia-Cuetos et al. 2012).

To date, all stable cultures of $M$. rubrum have been established using prey of either Teleaulax or Geminigera (Gustafson et al. 2000, Hansen \& Fenchel 2006, Johnson et al. 2006, Park et al. 2007), which form a

(C) The authors 2017. Open Access under Creative Commons by Attribution Licence. Use, distribution and reproduction are unrestricted. Authors and original publication must be credited. 
well-supported subclade of cryptophytes along with Plagioselmis (Deane et al. 2002, Hoef-Emden 2008). Feeding experiments with cultured M. rubrum are consistent with the notion that species from this cryptophyte subclade are preferred prey for M. rubrum; however, it will ingest species from outside of this clade as well (Park et al. 2007, Hansen et al. 2012). Further, it is thought that the availability of suitable cryptophyte prey is important for $M$. rubrum bloom formation (Herfort et al. 2011). The preferential consumption of certain cryptophyte species by M. rubrum would likely shape cryptophyte community composition, especially during blooms (Park et al. 2007).

Molecular tools have enabled more precise studies on $M$. rubrum plastid origin and retention dynamics (Johnson et al. 2007, Herfort et al. 2011, Hansen et al. 2012); however, questions remain regarding whether certain plastid types are selected by the ciliate for sequestration or proliferate more efficiently once taken up. Studies of natural populations of M. rubrum from temperate regions, using single-cell PCR, also converge upon a perspective that although the ciliate is capable of ingesting different species of cryptophytes, mainly $T$. amphioxeia plastids are found from wild $M$. rubrum populations (Nishitani et al. 2010, Herfort et al. 2011). These observations suggest that either temperate $M$. rubrum populations selectively retain $T$. amphioxeia plastids, or they are numerically dominant because of higher encounter rates (e.g. due to abundance).

In the present study, we performed laboratory experiments with a temperate $M$. rubrum strain and 3 cryptophyte species, Storeatula major, T. amphioxeia and T. acuta, to test the hypothesis that T. amphioxeia plastids are selected over and perform better (i.e. supporting higher growth rate) than plastids from other cryptophytes. While $T$. amphioxeia is commonly encountered in coastal ecosystems, its close relative $T$. acuta is less frequently reported and its plastids are rarely found in M. rubrum cells (Johnson et al. 2016). The cryptophyte $S$. major was isolated from the same ecosystem as our $M$. rubrum culture, i.e. Chesapeake Bay, and has been shown to be ingested at high rates when offered to mixotrophic dinoflagellates (Li et al. 2000).

\section{MATERIALS AND METHODS}

\section{Cultures}

Two closely related cryptophyte species, Teleaulax acuta (Butcher) Hill, 1991 and T. amphioxeia (W. Con- rad) Hill, 1991, as well as Storeatula major Butcher ex Hill, 1991 were used in this study. T. acuta was obtained from the Scandinavian Culture Collection of Algae and Protozoa (SCCAP; K-1486); T. amphioxeia (GCEP01) was isolated from Eel Pond, Falmouth, MA, USA by Dr. Mengmeng Tong; and S. major (strain SM or g) was isolated from the Choptank River, Cambridge, MD, a tributary of the Chesapeake Bay, USA, by Allen Lewitus. The cryptophytes were maintained in $250 \mathrm{ml}$ flasks in $15 \mathrm{psu} f / 2$ or $\mathrm{f} / 4$ medium (Guillard \& Ryther 1962), under a $14 \mathrm{~h}$ light:10 h dark cycle at a light level of $54 \mu \mathrm{mol} \mathrm{m}{ }^{-2} \mathrm{~s}^{-1}$ and at $15^{\circ} \mathrm{C}$.

Mesodinium rubrum was isolated by the senior author (M.D.J.) in October 2011 from the mouth of the James River in Chesapeake Bay (strain CBJR05), and cultured in the same conditions as the cryptophytes, but in 6 well plates $\left(12 \mathrm{ml} \mathrm{well}^{-1}\right)$ or $250 \mathrm{ml}$ tissue culture flasks. The culture was originally isolated, and since maintained, upon the cryptophyte GCEP01 as prey. Strain CBJR05 is from a new clade (G) of M. rubrum-like ciliates (Johnson et al. 2016), based on $18 \mathrm{~S}$, internally transcribed spacer region (ITS), and 28S ribosomal RNA gene sequences (Herfort et al. 2011, Garcia-Cuetos et al. 2012). Depending on the purpose of the experiment, the stock cultures of $M$. rubrum were fed once a week either with $T$. amphioxeia or $T$. acuta. The acclimation period with $T$. acuta was $4 \mathrm{wk}$, and $M$. rubrum was re-isolated from that culture for Expt 3, in order to remove traces of $T$. amphioxeia. It was also verified with quantitative PCR (qPCR) that M. rubrum had solely T. acuta plastids in the beginning of that experiment (not shown).

\section{Washing prey from Mesodinium rubrum cells}

M. rubrum cells were washed free of cryptophyte prey using $8.0 \mu \mathrm{m}$ Transwell (Corning) inserts in 12 well plates. To wash stock cultures for setting up experiments, approximately $50-100 \mathrm{ml}$ of culture was passed through the filter, and then washed with $200 \mathrm{ml}$ of filtered seawater. This concentrate of M. rubrum cells was then enumerated and used for experiments. For qPCR sampling, $2 \mathrm{ml}$ from each treatment were flushed with $100-150 \mathrm{ml}$ of filtered seawater using Transwell inserts, and the removal of free cryptophyte cells was confirmed under a microscope at 100x magnification (Fig. S1 in the Supplement at www.int-res.com/articles/suppl/a078p147 supp.pdf). $M$. rubrum cells were then collected on $25 \mathrm{~mm} \mathrm{GF} / \mathrm{C}$ filters (Whatman) and stored at $-20^{\circ} \mathrm{C}$ for not more than $24 \mathrm{~h}$ before DNA extraction. 
Functional and numerical response of Mesodinium rubrum to single cryptophyte prey

Grazing experiments were conducted using M. rubrum acclimated to the tested prey. However, we were unable to acclimate $M$. rubrum to $S$. major and found no evidence of predation on this cryptophyte. In order to acclimate $M$. rubrum to $T$. acuta, ciliates were washed free of their original prey, T. amphioxeia (as described above), and grown for at least 1 mo prior to experiments with weekly additions of $T$. acuta and f $/ 4$ media. Grazing experiments were conducted in 24 well plates in triplicate, and were sampled at the same time once a day for $2 \mathrm{~d}$ in order to estimate grazing rates. We measured the functional grazing response of $M$. rubrum to cryptophytes by placing $500-1000$ ciliates $\mathrm{ml}^{-1}$ with $T$. amphioxeia at concentrations of $0-30000$ cells ml ${ }^{-1}$, and 1000 ciliates $\mathrm{ml}^{-1}$ with $0-20000 \mathrm{~T}$. acuta $\mathrm{ml}^{-1}$. Growth $(\mu)$ and grazing rates, including the grazing constant (g), clearance rate $(F)$, and ingestion rate (IR), were determined using equations described previously (Frost 1972, Heinbokel 1978, Jeong \& Latz 1994). Grazing rates were all calculated after $24 \mathrm{~h}$ for assessment of the functional response to prey concentration and species, while growth rates were measured over 5-6 d. In addition, grazing rates were also determined for one experiment where plastid content was estimated and identification ensured with qPCR (see next subsection).

\section{Mesodinium rubrum plastid dynamics when offered mixed prey}

Prior to all experiments, $M$. rubrum cultures were not fed with fresh prey for $2 \mathrm{wk}$, and they were further starved for 2 additional days after washing cultures with seawater. All experiments were conducted in 6 well plates with treatments in duplicate, and in the same growth treatments detailed in 'Cultures' section with $\mathrm{f} / 2$ media. $M$. rubrum cells were washed (see 'Washing prey from Mesodinium rubrum cells' above) prior to the start of the experiments (from stock cultures) as well as at every sampling time point, in order to remove free-living prey. Only cryptophyte cultures that were in exponential growth phase were used in the experiments.

In the first plastid dynamics (PD) experiment, we examined whether $M$. rubrum sequesters plastids from a non-Teleaulax cryptophyte. M. rubrum, acclimated to $T$. amphioxeia, was fed with $T$. amphioxeia and $S$. major (predator:prey 1:7), mixed at ratios of
$1: 1,1: 2,1: 4,1: 8$ and 1:16, respectively. This was also a short-term experiment, and the samples for qPCR were taken at time $0\left(T_{0}\right)$, and after 6,24 and $48 \mathrm{~h}$. M. rubrum controls without prey as well as prey controls without $M$. rubrum were run in parallel in each experiment.

In PD Expt 2, we studied the short-term exchange of $M$. rubrum plastids and prey selection. In this experiment, $M$. rubrum, acclimated to $T$. amphioxeia, was fed with 1:0, 1:1 or 1:5 reciprocal combinations of T. amphioxeia and T. acuta, respectively (predator: prey 1:20). Samples for qPCR were taken at the following times: $0,2,5,24$ and $48 \mathrm{~h}$.

For studying growth, grazing, and prey selection of M. rubrum fed 2 Teleaulax spp. over a longer period (2 wk; PD Expt 3), a stock culture of M. rubrum acclimated to $T$. amphioxeia was fed several cryptophyte prey treatments with an increasing proportion of $T$. acuta. In the experiment, $T$. amphioxeia and T. acuta were combined at ratios of 1:0, 0:1,1:1, 1:2 or 1:10 to each another, respectively. The total predator:prey ratio was 1:15. Samples for cell counts were taken at $\mathrm{T}_{0}$ and on Days 2, 4, 7, 10 and 14. Samples to evaluate plastid intake and retention by $M$. rubrum using qPCR were taken at times 0 and $4 \mathrm{~h}$, and at 4,7 and $14 \mathrm{~d}$. Unlike the grazing functional response experiments (see 'Functional and numerical response of Mesodinium rubrum to single cryptophyte prey' above), we calculated grazing rates for this experiment over $2 \mathrm{~d}$.

Finally, the effect of $M$. rubrum feeding history on their prey selection (PD Expt 4) was studied with M. rubrum originally acclimated to pure cultures of either only $T$. amphioxeia or $T$. acuta. The predator: prey ratio was $1: 5$, and the given prey ratios were 1:0, $0: 1$ or 1:1 combinations of $T$. amphioxeia and T. acuta, respectively. Samples for qPCR were taken at the following times: 0 , and 3 and $7 \mathrm{~d}$.

\section{Cell enumeration and determination of rates}

Samples of $M$. rubrum and cryptophyte algae were preserved with $1 \%$ acid Lugol's solution (final), and enumerated using a Sedgewick-Rafter counting chamber and a compound Zeiss AxioScope A1 at 200x magnification for cryptophytes and 100x for M. rubrum. In all cases, at least 100 cells were counted. Growth and grazing rates (grazing coefficient, clearance rate, and ingestion rate) were calculated using the equations of Frost (1972) and Heinbokel (1978), and refined by Jeong \& Latz (1994) and Kim et al. (2008). 


\section{DNA extraction, primers and qPCR amplification}

The ingestion and retention of Teleaulax spp. and $S$. major plastids by $M$. rubrum was detected with qPCR. All samples were washed (see 'Washing prey from Mesodinium rubrum cells' above) prior to extraction and GPCR analysis, and DNA was extracted from the GF/C filters using cetrimonium bromide (CTAB) (Gast et al. 2004). A qPCR assay was designed for a fragment of the plastid-encoded large subunit of RuBisCO (rbcL) gene for each species of cryptophyte, whereas abundance of $M$. rubrum was determined by targeting a fragment of the nuclear small subunit (SSU) rRNA (18S) gene (Table 1). All primers were synthesized by Eurofins MWG Operon (AL, USA), and were designed to target regions that had mismatches with non-target species. The specificity of the primers was crosschecked with qPCR by assessing amplification cycle threshold $\left(C_{\mathrm{t}}\right)$ and melting temperature under a range of temperature settings (not shown). Assay conditions were optimized to amplify target template sequence and to exclude non-specific amplification of other cryptophyte species. Standard curves for cryptophytes were prepared in serial dilution of duplicate DNA extractions of 50,500,5000, 10000,50000 and 150000 cells ml$^{-1}$, and for M. rubrum 50, 100, 500, 3000, 5000, 8000 and 13000 cells ml$^{-1}$. All qPCR analyses were conducted using a Bio-Rad CFX96 Real-Time PCR detection system with SsoFast EvaGreen Supermix (Bio-Rad; reaction volume: $20 \mu \mathrm{l}$, primer concentration: $0.3 \mu \mathrm{M}$ ). The thermal program was as follows: $95^{\circ} \mathrm{C}$ for $3 \mathrm{~min}$ $(1 \mathrm{x}) ; 95^{\circ} \mathrm{C}$ for $10 \mathrm{~s}$ and primer-specific temperature (Table 1) for $30 \mathrm{~s}$, and a total of 40 cycles. Melting curve analysis was used to verify amplicon purity, and the copy numbers were determined from the $C_{\mathrm{t}}$ value and by using the standard curves (Bowers et al. 2000). Plastid number per cell in M. rubrum was then determined by taking the ratio of total cryptophyte plastids to the number of $M$. rubrum from the qPCR $C_{\mathrm{t}}$ data.

\section{Statistical analysis}

The effect of the 2 prey species and their different proportions on $M$. rubrum clearance and ingestion rates, and grazing coefficients were analysed with ANOVA, whereas $M$. rubrum growth rates were examined with the nonparametric Kolmogorov-Smirnov test. The possible prey selection due to previous feeding history was analysed with ANOVA, and the effect of different proportions of T. acuta and T. amphioxeia was tested with the nonparametric Jonckheere-Terpstra test, in which the abundance of T. acuta was considered as an ordering alternative. All statistical tests were conducted with IBM SPSS Statistics 22.

\section{RESULTS}

\section{Functional and numerical response of Mesodinium rubrum to single cryptophyte prey}

We were unable to find evidence that Mesodinium rubrum grazed on Storeatula major, and it failed to support growth of the ciliate, so no results are shown for this prey species. M. rubrum grazing coefficients (g) declined exponentially with increasing prey concentrations with Teleaulax amphioxeia, while the decline was linear for $T$. acuta (Table 2). Maximum $g$ for $T$. amphioxeia and T. acuta prey were both high, at $3.8 \pm 0.06$ and $3.2 \pm 0.52 \mathrm{~d}^{-1}$, respectively (Table 2 ), but overall population-level grazing on $T$. acuta was significantly higher (ANOVA, $F_{1,8}=5.97, \mathrm{p}=0.0239$ ). However, the cell-specific grazing rates for clearance (F) (ANOVA, $F_{1,8}=10.93, \mathrm{p}=0.0035$ ) and ingestion (IR) $\left(\right.$ ANOVA, $\left.F_{1,8}=11.51, \mathrm{p}=0.0029\right)$ were greater for T. amphioxeia prey. Maximum F and IR for $M$. rubrum were $6.8 \pm 1.9$ and $3.0 \pm 0.4 \mu \mathrm{cell}^{-1} \mathrm{~d}^{-1}$ (Fig. 1a), and $13.0 \pm 0.7$ and $8.2 \pm 0.7$ prey cell ${ }^{-1} \mathrm{~d}^{-1}$ (Fig. 1b) for T. amphioxeia and T. acuta, respectively. Growth rates of $M$. rubrum were nearly identical

Table 1. Primers used for quantitative PCR assays in this study to enumerate cryptophyte plastids

\begin{tabular}{|llc|}
\hline Primer & Sequence & Temperature $\left({ }^{\circ} \mathrm{C}\right)$ \\
\hline Teleaulax acuta 683F & 5'-TGC TGA GTT CGG TAA AGA GCT-3' & 64.2 \\
Teleaulax acuta 830R & 5'-ACG AGC GTA TGT AGA GTT ACC T-3' & \\
Teleaulax amphioxeia F1 & 5'-CTT CCT TAA AGA TGA CGA GAA CAT T-3' & 62.8 \\
Teleaulax amphioxeia R1 & 5'-TGA CCT TTA ATT TCA CCT GTA GCT-3' & \\
Storeatula major 600F & 5'-AGA GCT GCT GCT GGT ACT G-3' & 64.6 \\
Storeatula major 780R & 5'-CTG TTC TTA CGA GCC CAG ATA C-3' & \\
Mesodinium rubrum 405F & 5'-TAC CCA ATG CAG ACA CTG TGA G-3' & 64.5 \\
Mesodinium rubrum 524R & 5'-CCA GAC TTT CCC ATC AGT TGC TA-3' \\
\hline
\end{tabular}


Table 2. Functional grazing response of Mesodinium rubrum (MR) to Teleaulax amphioxeia (Tam) and T. acuta (Tac). Prey and predator concentrations at the beginning of the experiment $\left(\mathrm{T}_{0}\right)$, growth rate $(\mu)$ of predator and prey, and grazing constant $(\mathrm{g})$ after $24 \mathrm{~h}$. Rates are mean $\pm \mathrm{SD}(\mathrm{n}=3)$

\begin{tabular}{|c|c|c|c|c|c|c|c|}
\hline Prey & $\begin{array}{l}\text { Carbon in prey } \\
\text { at } \mathrm{T}_{0}\left(\mathrm{ng} \mathrm{C} \mathrm{ml} \mathrm{Cl}^{-1}\right)\end{array}$ & $\begin{array}{l}\text { Prey at } \mathrm{T}_{0} \\
\left(\text { cells } \mathrm{ml}^{-1} \text { ) }\right.\end{array}$ & $\begin{array}{l}\mathrm{MR} \text { at } \mathrm{T}_{0} \\
\left(\text { cells } \mathrm{ml}^{-1}\right)\end{array}$ & $\begin{array}{l}\text { Prey:MR } \\
\text { ratio at } \mathrm{T}_{0}\end{array}$ & $\begin{array}{c}\mathrm{MR} \mu \\
\left(\mathrm{d}^{-1}\right)\end{array}$ & $\begin{array}{l}\text { Prey } \mu \\
\left(d^{-1}\right)\end{array}$ & $\underset{\left(d^{-1}\right)}{g}$ \\
\hline \multirow[t]{7}{*}{ Tam } & 0 & 0 & 610 & 0 & $0.03 \pm 0.05$ & - & - \\
\hline & 55 & 600 & 530 & 1 & $0.21 \pm 0.09$ & $0.44 \pm 0.13$ & $3.81 \pm 0.06$ \\
\hline & 124 & 1500 & 710 & 2 & $0.12 \pm 0.03$ & $0.52 \pm 0.07$ & $2.37 \pm 0.23$ \\
\hline & 285 & 3200 & 620 & 5 & $0.27 \pm 0.09$ & $0.60 \pm 0.05$ & $1.27 \pm 0.21$ \\
\hline & 634 & 7000 & 630 & 11 & $0.31 \pm 0.04$ & $0.60 \pm 0.07$ & $1.08 \pm 0.21$ \\
\hline & 1120 & 12500 & 670 & 19 & $0.33 \pm 0.05$ & $0.65 \pm 0.06$ & $0.69 \pm 0.10$ \\
\hline & 2540 & 28000 & 630 & 44 & $0.37 \pm 0.12$ & $0.72 \pm 0.11$ & $0.28 \pm 0.03$ \\
\hline \multirow[t]{7}{*}{ Tac } & 0 & 0 & 930 & 0 & $0.14 \pm 0.01$ & - & - \\
\hline & 73 & 730 & 990 & 1 & $0.16 \pm 0.05$ & $0.02 \pm 0.13$ & $3.19 \pm 0.52$ \\
\hline & 150 & 1500 & 810 & 2 & $0.23 \pm 0.07$ & $0.20 \pm 0.03$ & $2.72 \pm 0.11$ \\
\hline & 330 & 3300 & 840 & 4 & $0.34 \pm 0.06$ & $0.26 \pm 0.05$ & $2.87 \pm 0.29$ \\
\hline & 680 & 6800 & 890 & 8 & $0.32 \pm 0.02$ & $0.24 \pm 0.05$ & $2.01 \pm 0.27$ \\
\hline & 1200 & 12000 & 940 & 13 & $0.40 \pm 0.02$ & $0.23 \pm 0.13$ & $1.10 \pm 0.29$ \\
\hline & 2150 & 21500 & 880 & 24 & $0.36 \pm 0.04$ & $0.25 \pm 0.04$ & $0.42 \pm 0.04$ \\
\hline
\end{tabular}
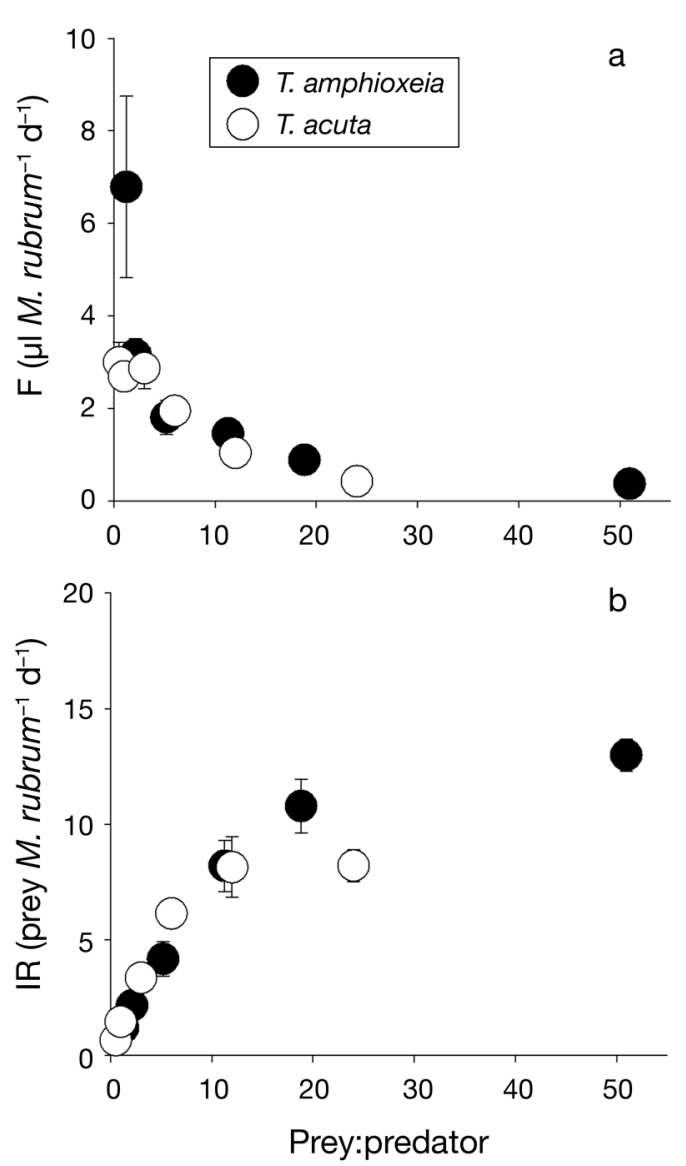

Fig. 1. Mesodinium rubrum grazing response $(\mathrm{n}=3)$ as a function of Teleaulax amphioxeia and T. acuta prey:predator ratio (at $\mathrm{T}_{0}$ ). (a) Clearance $(\mathrm{F})$ and (b) ingestion (IR) rates of $M$. rubrum on prey. Error bars are SD

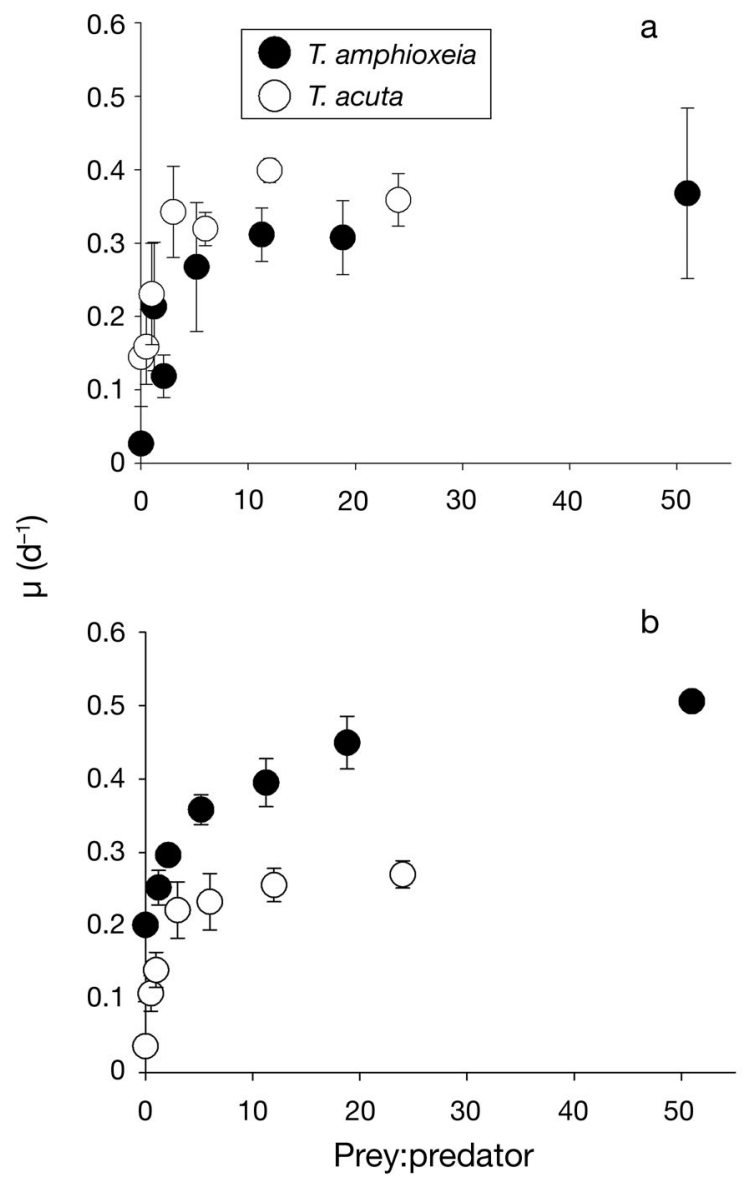

Fig. 2. Growth rate $(\mu)$ response $(n=3)$ of Mesodinium rubrum as a function of Teleaulax amphioxeia and T. acuta prey:predator ratio (at $\mathrm{T}_{0}$ ) after (a) $2 \mathrm{~d}$ and (b) 5-6 d. Error bars are SD 
over the first $2 \mathrm{~d}$ (Fig. 2a), with maximum growth rates reaching $0.62 \pm 0.07$ and $0.56 \pm 0.14 \mathrm{~d}^{-1}$ during that time (from Day 1 to Day 2; not shown) when grown with $T$. amphioxeia and $T$. acuta, respectively. Over longer periods (5-6 d), however, $\mu$ of $M$. rubrum was significantly higher in T. amphioxeia (Fig. 2b).

\section{Mesodinium rubrum growth, grazing, and PD with mixed cryptophyte prey}

While we found no evidence of ingestion of $S$. major prey or retention of its plastids during the functional response experiment (see previous subsection), we decided to use it in a mixed-prey experiment with T. amphioxeia in order to see if we could detect ingestion of $S$. major using qPCR (PD Expt 1). All treatments that included $S$. major resulted in negative growth rates of $M$. rubrum, even if $T$. amphioxeia was also added (Table 3 ), and no evidence of $S$. major was detected in M. rubrum using qPCR in any of our treatments. Thereafter, all mixed-prey experiments utilized $T$. amphioxeia and $T$. acuta.

In order to determine if mixed Teleaulax prey has an effect upon M. rubrum grazing or growth rates, we measured prey selection and PD of $M$. rubrum grazing on $T$. amphioxeia, $T$. acuta, or mixtures of the 2 at different ratios, but identical prey concentrations. PD Expt 2 had the highest predator:prey ratio $(1: 20)$, and after $48 \mathrm{~h}$, this resulted in the greatest average number of plastids per cell (16-17) that we observed in this M. rubrum strain (Fig. 3). M. rubrum plastid intake began soon after they were introduced to new prey, as T. acuta plastids were detected in M. rubrum after $2 \mathrm{~h}$ (earliest time point) and total plastid numbers more than doubled following their introduction. This change in the number of plastids from a different prey source was rapid and M. rubrum replaced half of its plastids with $T$. acuta after $24 \mathrm{~h}$ when fed with a 5:1 ratio (Fig. 3). M. rubrum did not strongly discriminate between Teleaulax plastid sources, and the proportion of $T$. amphioxeia and

Table 3. Plastid dynamics (PD) experiments to assess if Mesodinium rubrum (MR) selects prey between Teleaulax amphioxeia (Tam), T. acuta (Tac), and Storeatula major (SM), and if prey organelle acclimation state affects prey selection. Average growth rates $\left(\mu_{\mathrm{avg}}, \pm \mathrm{SD}\right)$ were estimated over the entire time of the experiment, while maximum growth rates $\left(\mu_{\max } \pm \mathrm{SD}\right)$ were between 2 time points. TPG: Teleaulax/Plagioselmis/Geminigera. ${ }^{*}$ Significant difference $(p<0.05)$

\begin{tabular}{|c|c|c|c|c|c|c|c|}
\hline $\begin{array}{l}\text { MR } \\
\text { (cells ml }{ }^{-1} \text { ) }\end{array}$ & $\begin{array}{c}\text { Prey } \\
\text { (acclimation) }\end{array}$ & $\begin{array}{c}\text { Prey } \\
\text { (cells ml }^{-1} \text { ) }\end{array}$ & Treatment & $\begin{array}{l}\text { MR:prey } \\
\text { ratio }\end{array}$ & $\begin{array}{c}\text { Tam:Tac/SM } \\
\text { ratio }\end{array}$ & $\underset{\left(\mathrm{d}^{-1}\right)}{\mathrm{MR} \mu_{\mathrm{avg}}}$ & $\underset{\left(\mathrm{d}^{-1}\right)}{\mathrm{MR} \mu_{\max }}$ \\
\hline \multicolumn{8}{|c|}{ PD Expt 1: plastid sequestration from a non-TPG clade cryptophyte (Tam vs. SM; 2 d) } \\
\hline 400 & Tam & 3000 & Single prey & $1: 7$ & $1: 0$ & $0.06 \pm 0.02$ & $0.06 \pm 0.02$ \\
\hline 400 & Tam & 3000 & Single prey & $1: 7$ & $0: 1$ & $-0.15 \pm 0.13$ & $-0.07 \pm 0.09$ \\
\hline 400 & Tam & 3000 & Mixed prey & $1: 7$ & $1: 1$ & $-0.21 \pm 0.06$ & $-0.21 \pm 0.06$ \\
\hline 400 & Tam & 3000 & Mixed prey & $1: 7$ & $1: 2$ & $-0.16 \pm 0.20$ & $-0.16 \pm 0.20$ \\
\hline 400 & Tam & 3000 & Mixed prey & $1: 7$ & $1: 4$ & $-0.26 \pm 0.12$ & $-0.08 \pm 0.27$ \\
\hline 400 & Tam & 3000 & Mixed prey & $1: 7$ & $1: 8$ & $-0.41 \pm 0.15$ & $-0.39 \pm 0.59$ \\
\hline 400 & Tam & 3000 & Mixed prey & $1: 7$ & $1: 16$ & $-0.28 \pm 0.18$ & $-0.28 \pm 0.18$ \\
\hline \multicolumn{8}{|c|}{ PD Expt 2: short-term (2 d) exchange of MR plastids and prey (Tam vs. Tac) selection } \\
\hline 300 & Tam & 6000 & Single prey & $1: 20$ & $1: 0$ & $0.22 \pm 0.04$ & $0.22 \pm 0.04$ \\
\hline 300 & Tam & 6000 & Single prey & $1: 20$ & $0: 1$ & $0.02 \pm 0.08$ & $0.02 \pm 0.08$ \\
\hline 300 & Tam & 6000 & Mixed prey & $1: 20$ & $1: 1$ & $0.04 \pm 0.07$ & $0.05 \pm 0.19$ \\
\hline 300 & Tam & 6000 & Mixed prey & $1: 20$ & $1: 5$ & $0.02 \pm 0.03$ & $0.02 \pm 0.03$ \\
\hline 300 & Tam & 6000 & Mixed prey & $1: 20$ & $5: 1$ & $0.14 \pm 0.08$ & $0.14 \pm 0.08$ \\
\hline \multicolumn{8}{|c|}{ PD Expt 3: long-term (14 d) exchange of MR plastids and prey (Tam vs. Tac) selection } \\
\hline 300 & Tam & 4500 & Single prey & $1: 15$ & $1: 0$ & $0.07 \pm 0.01$ & $0.25 \pm 0.06$ \\
\hline 300 & Tam & 4500 & Single prey & $1: 15$ & $0: 1$ & $0.12 \pm 0.03$ & $0.29 \pm 0.06$ \\
\hline 300 & Tam & 4500 & Mixed prey & $1: 15$ & $1: 1$ & $0.07 \pm 0.02$ & $0.32 \pm 0.02$ \\
\hline 300 & Tam & 4500 & Mixed prey & $1: 15$ & $1: 2$ & $0.09 \pm 0.02$ & $0.19 \pm 0.07$ \\
\hline 300 & Tam & 4500 & Mixed prey & $1: 15$ & $1: 10$ & $0.11 \pm 0.02$ & $0.26 \pm 0.02$ \\
\hline \multicolumn{8}{|c|}{ PD Expt 4: effect of MR feeding history on their prey (Tam vs. Tac) selection ( $7 \mathrm{~d}$ ) } \\
\hline 300 & Tam & 1500 & Single prey & $1: 5$ & $1: 0$ & $0.08 \pm 0.02$ & $0.14 \pm 0.06$ \\
\hline 300 & Tam & 1500 & Single prey & $1: 5$ & $0: 1$ & $0.12 \pm 0.06$ & $0.12 \pm 0.06$ \\
\hline 300 & Tam & 1500 & Mixed prey & $1: 5$ & $1: 1$ & $0.18 \pm 0.02$ & $0.25 \pm 0.03^{*}$ \\
\hline 300 & Tac & 1500 & Mixed prey & $1: 5$ & $1: 0$ & $0.10 \pm 0.02$ & $0.10 \pm 0.02$ \\
\hline 300 & Tac & 1500 & Mixed prey & $1: 5$ & $0: 1$ & $0.15 \pm 0.06$ & $0.15 \pm 0.06$ \\
\hline 300 & Tac & 1500 & Mixed prey & $1: 5$ & $1: 1$ & $0.07 \pm 0.02$ & $0.07 \pm 0.02^{*}$ \\
\hline
\end{tabular}



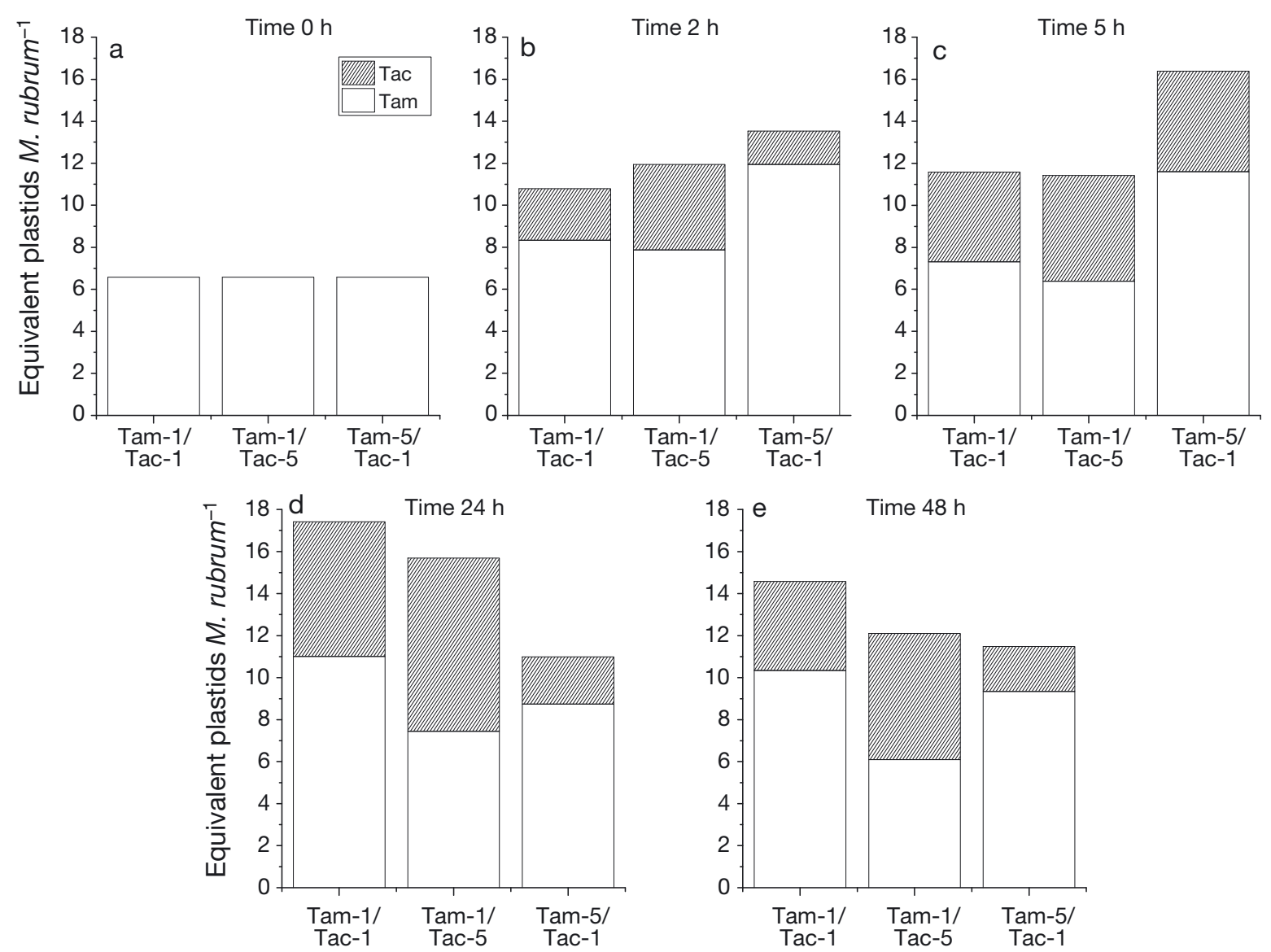

Fig. 3. Short-term (48 h) plastid dynamics (PD) in Mesodinium rubrum as determined by qPCR (PD Expt 2) at times (a) 0, (b) $2 \mathrm{~h}$, (c) $5 \mathrm{~h}$, (d) $24 \mathrm{~h}$, and (e) 48 h. M. rubrum was acclimated to Teleaulax amphioxeia (Tam) prey and fed Tam and T. acuta (Tac) at a prey:predator ratio of 20:1. Three treatments varied the ratio of Tam:Tac prey at 1:1 (Tam-1/Tac-1), 1:5 (Tam-1/ Tac-5), and 5:1 (Tam-5/Tac-1). Tac plastids could be detected in M. rubrum $2 \mathrm{~h}$ after their introduction (ANOVA, $\mathrm{p}<0.05)$. Stacked bar graphs are means $(\mathrm{n}=2)$

T. acuta plastids in M. rubrum seemed largely dependent on the given proportions of these 2 cryptophytes when $M$. rubrum was fed with mixed prey (Jonckheere-Terpstra, $\mathrm{p}<0.01$; Expt 2; Fig. 3). However, the 1:5 T. amphioxeia:T. acuta treatment only resulted in about $30-40 \%$ more $T$. acuta plastids in $M$. rubrum compared to the 1:1 prey mix after $48 \mathrm{~h}$, indicating that either IR was low (not measured here), the ciliate became satiated in this experiment, or that they selected against $T$. acuta prey. Regardless, Teleaulax prey species did not affect $M$. rubrum growth rate $(\mu)$ (Kolmogorov-Smirnov, $p>0.05$ ), which after $2 \mathrm{~d}$ ranged between 0.19 and $0.27 \mathrm{~d}^{-1}$ (Table 4).

Table 4. Growth $(\mu)$ and grazing parameters (g: grazing constant, F: clearance rate, IR: ingestion rate) for Mesodinium rubrum (MR) fed various Teleaulax (Tam: T. amphioxeia, Tac: T. acuta) prey combinations during plastid dynamics Expt 3 after 48 h. Values are mean $\pm \mathrm{SD}(\mathrm{n}=2)$. Predator:prey ratio at $\mathrm{T}_{0}$ was $1: 15$

\begin{tabular}{|lccccc|}
\hline Treatment (Tam:Tac ratio) & Prey $\mu\left(\mathrm{d}^{-1}\right)$ & $\mathrm{MR} \mu\left(\mathrm{d}^{-1}\right)$ & $\mathrm{g}\left(\mathrm{d}^{-1}\right)$ & $\mathrm{F}\left(\mu \mathrm{l} \mathrm{MR} \mathrm{d}^{-1}\right)$ & $\mathrm{IR}\left(\mathrm{prey} \mathrm{MR}-1 \mathrm{~d}^{-1}\right)$ \\
\hline Tam only (1:0) & $0.44 \pm 0.08$ & $0.25 \pm 0.06$ & $1.01 \pm 0.12$ & $2.05 \pm 0.07$ & $7.64 \pm 0.90$ \\
Tac only (0:1) & $0.53 \pm 0.04$ & $0.24 \pm 0.04$ & $0.71 \pm 0.04$ & $1.64 \pm 0.44$ & $5.85 \pm 1.51$ \\
Tam-1/Tac-1 (1:1) & $0.57 \pm 0.07$ & $0.27 \pm 0.04$ & $0.49 \pm 0.10$ & $1.16 \pm 0.10$ & $4.11 \pm 1.99$ \\
Tam-1/Tac-2 (1:2) & $0.46 \pm 0.02$ & $0.19 \pm 0.07$ & $0.65 \pm 0.08$ & $1.56 \pm 0.04$ & $6.25 \pm 0.34$ \\
Tam-1/Tac-10 (1:10) & $0.45 \pm 0.07$ & $0.26 \pm 0.02$ & $0.43 \pm 0.33$ & $0.96 \pm 0.77$ & $6.23 \pm 5.55$ \\
\hline
\end{tabular}


In PD Expt 3, we simultaneously measured the functional grazing and growth response as well as $\mathrm{PD}$ of $M$. rubrum in response to our mixed-prey treatments. No grazing parameters differed between the various prey ratio treatments (ANOVA, p > 0.05; Table 4) and, averaged across all treatments and combinations of Teleaulax prey, IRs in PD Expt 3 were $6.1 \pm 1.9$ prey predator ${ }^{-1} \mathrm{~d}^{-1}$. Also, M. rubrum growth kinetics were similar across treatments (Table 3; Fig. S2 in the Supplement at www.intres.com/articles/suppl/a078p147_supp.pdf). Calculations based on IR and cell abundance revealed that in this experiment ingestion, rather than plastid division, was sufficient to explain plastid content per cell during the first $4 \mathrm{~d}$. The prey:predator ratio in this experiment was 15:1, and plastids per cell in $M$. rubrum increased from 3 at $\mathrm{T}_{0}$ to between $4-10$ after $4 \mathrm{~h}$, and reached a maximum of 10-14 after $4 \mathrm{~d}$ (Fig. 4). Total $M$. rubrum plastid replacement from one species (T. amphioxeia) to the other (T. acuta) took $\sim 2 \mathrm{wk}$ and occurred when $M$. rubrum was fed with only the other Teleaulax species (Figs. 3-5).

In PD Expt 4, we tested whether prey acclimation state would affect uptake or selection of prey when offered separately or mixed. We found no differences in growth rate or total plastids per cell with prey acclimation state or treatment (Fig. 5). However, M. rubrum was more efficient at replacing $T$. amphioxeia
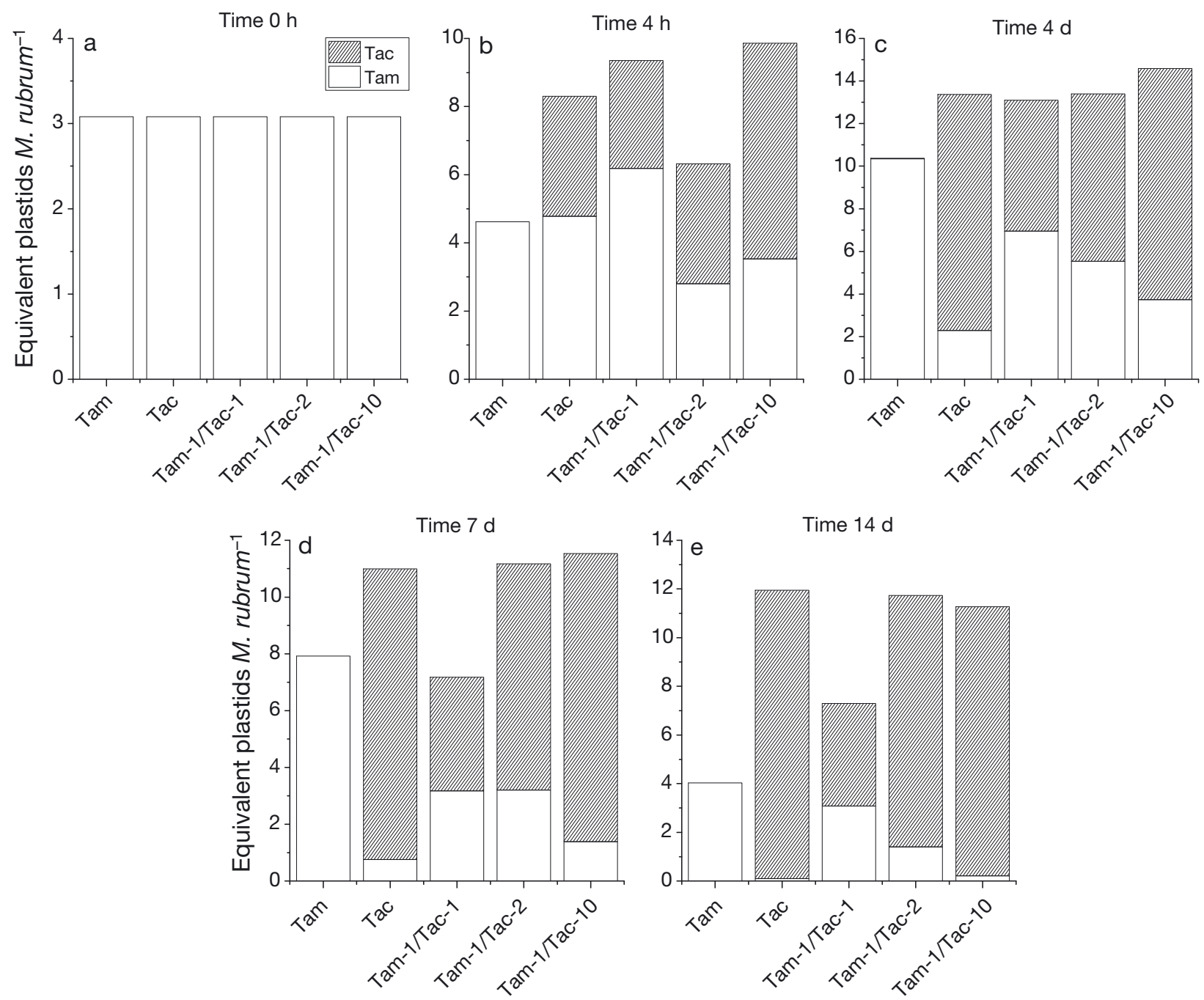

Fig. 4. Plastid dynamics (PD) in Mesodinium rubrum acclimated to Teleaulax amphioxeia (Tam) and fed Tam or T. acuta (Tac), or a 1:1 (Tam-1/Tac-1), 1:2 (Tam-1/Tac-2), or 1:10 (Tam-1/Tac-10) mix of the two (PD Expt 3), at time points (a) 0, (b) 4 h, (c) $4 \mathrm{~d}$, (d) $7 \mathrm{~d}$, and (e) $14 \mathrm{~d}$. Total prey:predator ratio in all treatments was 15:1. Plastid number and type determined using qPCR. The number of Tam and Tac plastids in M. rubrum was dependent on the given proportions of these 2 cryptophytes (Jonckheere-Terpstra test, $\mathrm{p}<0.01)$. Stacked bar graphs are means $(\mathrm{n}=2)$ 

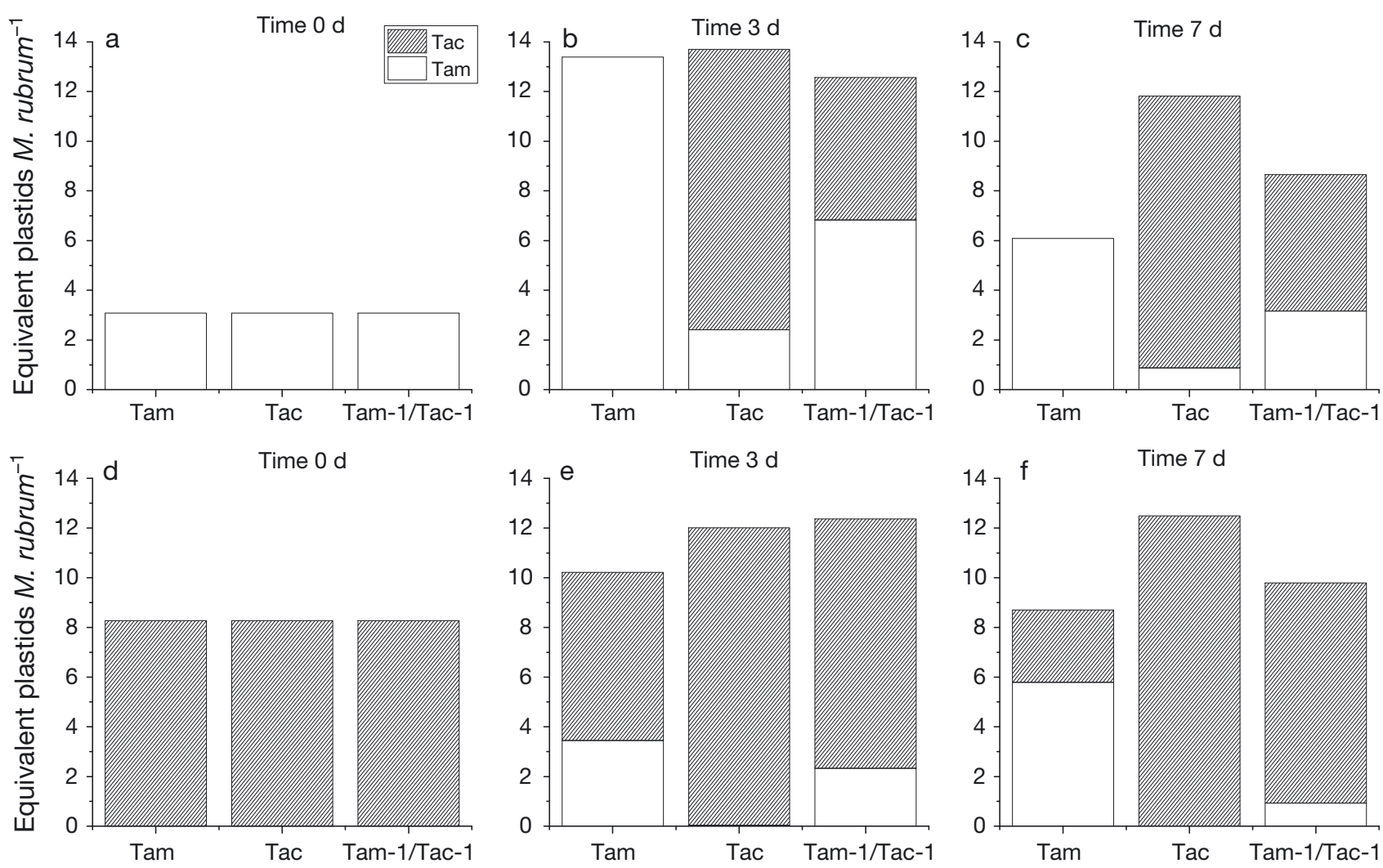

Fig. 5. Plastid dynamics (PD) in Mesodinium rubrum acclimated to either (a-c) Teleaulax amphioxeia (Tam) or (d-f) T. acuta (Tac) and fed those or a 1:1 mix (Tam-1/Tac-1) of them (PD Expt 4), at time points (a) 0, (b) 3 d, and (c) 7 d. Total prey:predator ratio in all treatments was 5:1. Plastid number and type were determined by qPCR. M. rubrum did not discriminate between the 2 Teleaulax plastid sources, and the feeding history of $M$. rubrum did not cause prey selection (ANOVA, p > 0.05). Stacked bar graphs are means $(\mathrm{n}=2)$

plastids with those from $T$. acuta than vice versa (ANOVA, $\mathrm{p}<0.05$ ). When fed only the other prey source, $\sim 70 \%$ of plastids were replaced with $T$. amphioxeia when acclimated to T. acuta, while $>90 \%$ were replaced by $T$. acuta when acclimated to $T$. amphioxeia. When fed a mix (1:1), the difference in replacement efficiency was similar, with $T$. acutaacclimated cells replacing only $\sim 15 \%$ of their plastids, while $T$. amphioxeia-acclimated cells replaced $\sim 35 \%$. In the mixed-prey treatment, these differences could be explained by competitive interactions between the prey, which appear to favor T. acuta (see PD Expt 3).

\section{Prey growth responses and evidence for competitive interactions from Mesodinium rubrum-free controls}

During the functional response experiments, $T$. amphioxeia $\left(\mu_{\max }=0.72 \pm 0.11 \mathrm{~d}^{-1}\right)$ had significantly higher growth rates (ANOVA, $\mathrm{p}<0.01$ ) than $T$. acuta $\left(\mu_{\max }=0.26 \pm 0.05 \mathrm{~d}^{-1}\right)$ within the predator-free controls (Table 2). However, we found no difference in the growth rates of the 2 Teleaulax species (T. amphioxeia: $\mu=0.73 \mathrm{~d}^{-1}$ and T. acuta: $\mu=0.77 \mathrm{~d}^{-1}$; ANOVA, p > 0.05) within our no-predator controls during the PD experiments. The effect of grazing on Teleaulax abundance was clear: the prey populations grew fast without $M$. rubrum, but remained at a constant level with $M$. rubrum (ANOVA, $\mathrm{p}<0.001$; Fig. S3 in the Supplement). Interestingly, the 2 Teleaulax species revealed evidence for competitive interactions during co-culture in PD Expt 3. The growth rates of $T$. amphioxeia and T. acuta were similar when grown separately, as were the combined prey growth rates in all mixed-prey treatments when they were grown without M. rubrum (Table 4). However, qPCR analysis of no-grazer controls revealed that the relative proportions of these prey species changed during co-culture, with $T$. acuta taking over in all mixed treatments within $4 \mathrm{~d}$. 


\section{DISCUSSION}

\section{A preference for Teleaulax}

Both field and laboratory studies on Mesodinium rubrum suggest that cryptophytes from the Teleaulax/Plagioselmis/Geminigera (TPG) clade support higher growth and are compatible for plastid sequestration (Yih et al. 2004, Johnson et al. 2006, Park et al. 2007, Nishitani et al. 2010, Herfort et al. 2011, Myung et al. 2011, Hansen et al. 2012, Rial et al. 2015). In temperate regions, both natural populations and cultured isolates of $M$. rubrum are almost always associated with T. amphioxeia-like plastids/prey (Nishitani et al. 2010, Herfort et al. 2011, Garcia-Cuetos et al. 2012, Riobó et al. 2013). In this study, we assessed the grazing functional response, growth, and plastid sequestration dynamics of $M$. rubrum when fed single or mixed populations of cryptophytes. Using species-specific qPCR assays for a plastid-encoded gene, we determined that the temperate $M$. rubrum strain CBJR05 did not ingest Storeatula major, but consumed both Teleaulax species and retained their plastids with essentially equal efficiency, with no short-term (1-2 d) difference in growth rates. The growth rates of our $M$. rubrum were similar to the growth rates of the other temperate $M$. rubrum strains (Park et al. 2007, Hansen et al. 2012). However, over longer periods (5-6 d), growth of M. rubrum on $T$. amphioxeia was higher than on $T$. acuta in one of our experiments.

It is reported that $M$. rubrum cells may simultaneously contain chloroplasts from different cryptophyte species (Nishitani et al. 2010, Myung et al. 2011, Hansen et al. 2012). With our quantitative analysis, we confirmed that $M$. rubrum can indeed have mixed plastids, and, if prey species are suitable, the retained plastid ratio reflects the proportions of the given prey. This suggests that the field observations of $M$. rubrum containing mainly $T$. amphioxeia plastids (Nishitani et al. 2010, Herfort et al. 2011) is perhaps due to this prey species being more abundant than other compatible TPG cryptophytes. Our results are also consistent with Teleaulax spp. having unique phenotypic traits compared to other cryptophyte taxa, e.g. S. major, that make them more attractive to $M$. rubrum as prey. Even if $M$. rubrum were ingesting but not retaining $S$. major plastids, we would expect to see some signal from qPCR of washed ciliates after a brief exposure period. The absence of both a qPCR signal as well as any detectable depression in $S$. major growth rate strongly suggests that $M$. rubrum did not ingest them. In addition to chloroplasts, $M$. rubrum also retains prey nuclei (kleptokaryon), which are transcriptionally active and apparently control photosynthesis in the ciliate (Johnson et al. 2007, Lasek-Nesselquist et al. 2015). While we did not study the role of the kleptokaryon here, our results imply that in certain circumstances, $M$. rubrum may simultaneously possess nuclei of multiple Teleaulax species as well as mismatched nuclei-plastid combinations. Since this likely occurred in our study with no apparent effect on growth rate of the ciliate, it raises intriguing questions regarding the molecular control, coordination and interaction of mixed foreign organelles in M. rubrum.

\section{A role for Mesodinium rubrum in shaping cryptophyte populations}

Like other $M$. rubrum strains (Gustafson et al. 2000), our culture began to feed immediately after their introduction to optimal cryptophyte prey; however, ingestion rates were higher than those reported previously (Yih et al. 2004, Hansen \& Fenchel 2006, Smith \& Hansen 2007). Factors explaining differences in reported $M$. rubrum ingestion rates are unclear; however, strain/variant type of both the ciliate and prey as well as feeding history of the ciliates likely play a role. Our results, together with results from these previous studies, suggest that $M$. rubrum may exert substantial grazing pressure (5-12 cryptophytes $M$. rubrum ${ }^{-1} \mathrm{~d}^{-1}$ ) on natural populations of Teleaulax cryptophytes, and suggest that when they encounter high concentrations are able to quickly ingest and assimilate prey organelles, fueling their population growth. In natural populations of M. rubrum within the Columbia River Estuary, North Pacific coast, USA, a novel mechanism of apparent rapid prey uptake has been observed using FlowCAM analysis of natural samples (Peterson et al. 2013). While this result was not likely a factor, these observations suggest that certain variants of the $M$. major/rubrum species complex may achieve even higher ingestion rates when cryptophyte prey are abundant. Our results also imply that grazing pressure exerted by M. rubrum may play a role in shaping cryptophyte diversity. The apparent prevalence of $T$. amphioxeia both in M. rubrum cells (Nishitani et al. 2010, Herfort et al. 2011) and in natural communities (Johnson et al. 2016) suggests that $T$. acuta may be a poor competitor in nature. However, our qPCR results of predator-free mixed Teleaulax prey controls suggests the opposite, with $T$. acuta becoming dominant within $4 \mathrm{~d}$. Reconciliation of these observa- 
tions may be found in the growth rates of $T$. amphioxeia and T. acuta, which, averaged across all experiments, were 0.61 and $0.38 \mathrm{~d}^{-1}$, respectively. The reason for lower growth rates in $T$. acuta during functional response experiments is unclear, and the higher growth rates measured during the PD experiment have not been repeated. Taken together, differences in Teleaulax growth rates, combined with extremely high grazing rates on both Teleaulax spp. by $M$. rubrum, may help to explain the apparent dominance of $T$. amphioxeia in nature (Johnson et al. 2016). This difference in population survival was manifested during our grazing functional response experiments to prey concentrations, where the grazing constant $(\mathrm{g})$ averaged across all prey:predator ratios was greater on $T$. acuta than on $T$. amphioxeia. However, numerous other factors could explain patterns of cryptophyte genetic diversity in natural ecosystems, and additional experiments on multiple strains of each Teleaulax sp. would be needed in order to test this conclusion.

\section{Comparisons of CBJR05 with other strains}

Our $M$. rubrum strain had on average 8-14 plastids cell $^{-1}$ when recently fed, which is consistent with other studies (Hansen \& Fenchel 2006, Johnson et al. 2006, 2007, Garcia-Cuetos et al. 2012), and it took $2 \mathrm{wk}$ to replace all sequestered plastids from one Teleaulax species to another. This time frame contrasts with the observations of Hansen et al. (2012), whose Danish $M$. rubrum strain needed a much longer time (i.e. $>35$ d) for full plastid turnover when switching from $T$. amphioxeia to $T$. acuta. The slower plastid turnover time for the Danish $M$. rubrum strain was most likely due to the much lower concentrations of prey used in that study (prey:predator ratio of 1), which likely resulted in a greater role of plastid division during the transition of $T$. amphioxeia to $T$. acuta plastids (Hansen et al. 2012). Our results demonstrate for the first time that at least one M. rubrum variant is capable of quickly turning over its plastids with those from another Teleaulax spp. by ingesting large amounts of prey and apparently sequestering their plastids, rather than de novo organelle division. These results suggest that the $M$. rubrum clade G (Johnson et al. 2016) strain used here may have less control over sequestered organelles compared to other strains. Further research is needed to directly compare plastid uptake, replacement, and de novo division of sequestered organelles among different M. rubrum clades in order to conclude how these processes differ within the group. One potential issue could be how well $M$. rubrum exploits organelles from different strains within T. amphioxeia as well as other species. Previous studies have shown that M. rubrum has variable growth rates when fed different T. amphioxeia strains (Park et al. 2007) and Teleaulax spp. (Rial et al. 2015).

Another important difference between the present study and Hansen et al. (2012) is the methodological approach for quantifying plastids. While we used qPCR to enumerate plastid types, Hansen et al. (2012) used PCR and cloning. When dealing with mixed templates, the use of qPCR with speciesspecific primers is less prone to biases that may affect traditional PCR, such as variations in template concentration, primer annealing efficiency due to base pair composition, and amplification efficiency due to amplicon size. The choice of gene to target for PCR and cloning is also important. While divergent gene sequences may provide a strong phylogenetic signal, they are also likely to possess sequence variations that mediate PCR bias. These concerns are particularly valid here, since Hansen et al. (2012) targeted the plastid nucleomorph SSU rRNA genes in cryptophytes, which are highly divergent and often possess unalignable regions (Hoef-Emden et al. 2002). While this result was unlikely a factor when discerning between the closely related Teleaulax sequences, it may have played a role with some of their negative results with non-TPG cryptophytes. However, their conclusions are also supported by transmission electron micrographs of M. rubrum fed non-TPG cryptophytes, which suggest that the ciliate digests these prey within food vacuoles rather than sequestering their organelles (Hansen et al. 2012). In contrast, a Korean M. rubrum strain (MR-MAL01) has been reported to ingest non-TPG clade cryptophytes and sequesters their plastids (Park et al. 2007, Myung et al. 2011). While we found no evidence of our $M$. rubrum strain ingesting $S$. major, this was the only non-Teleaulax cryptophyte that we tested in this study. While certain TPG cryptophytes clearly support optimal growth in $M$. rubrum and appear to be selected over other groups, more research is needed to determine if they can sequester and physiologically exploit organelles from other cryptophyte groups.

\section{A potential role for grazing in bloom formation}

It is suggested that $M$. rubrum bloom formation depends on the availability of suitable cryptophyte 
prey (Herfort et al. 2011). High concentrations of cryptophyte algae have been shown to co-occur with growing $M$. rubrum populations in the Columbia River Estuary, and decline as the bloom reaches its peak levels (Herfort et al. 2012). In Chesapeake Bay, high concentrations of cryptophyte algae were observed to occur within a tributary preceding localized blooms of $M$. rubrum, and decline when concentrations of the ciliate increase (Johnson et al. 2013). In coastal Korean waters, peaks in M. rubrum abundance appear to be positively correlated with that of cryptophytes (Kim et al. 2007, Yih et al. 2013). Our experiments demonstrate that $M$. rubrum is extremely effective in controlling Teleaulax prey populations, with grazing coefficients exceeding $1 \mathrm{~d}^{-1}$ at prey:predator ratios as high as 10:1. However, previous studies have also noted that certain $M$. rubrum strains are extremely efficient at exploiting foreign organelles by regulating and dividing them (Johnson \& Stoecker 2005, Johnson et al. 2007, Moeller et al. 2011), and that ingestion rates as low as 1 cryptophyte $M$. rubrum ${ }^{-1} \mathrm{~d}^{-1}$ are sufficient for supporting maximum growth (Yih et al. 2004, Smith \& Hansen 2007). The latter 2 research groups have also reported the percent carbon contributed from ingested prey (CCP) in $M$. rubrum cultures. A culture from Korean waters (clade B) was found to have a CCP of 0.06-5.54 (Yih et al. 2004), while a strain from coastal Denmark (clade F) was found to have values between 0.5-22 (Smith \& Hansen 2007). Our calculations using the same caveats discussed in Smith \& Hansen (2007) were 6-32\% for both Teleaulax species. While these results imply different physiological dependencies upon carbon through phagotrophic mixotrophy, we feel that such estimations in M. rubrum are inappropriate, given that much of the ingested carbon is retained as intact organelles. Rather, we interpret these differences as various clades of M. rubrum perhaps having different capacities for dividing cryptophyte organelles and therefore possessing different requirements for acquiring them (i.e. feeding rates). Further work is needed with different strains of M. rubrum and Teleaulax prey in order to better understand these dynamics.

Taken together, these results provide an emerging view that $M$. rubrum blooms may be fueled by 'luxury' uptake of cryptophyte organelles when optimal prey (e.g. Teleaulax spp.) are abundant, coupled with their highly adapted and extremely efficient mode of acquired phototrophy. Further studies that directly compare the functional response and physiological performance of $M$. rubrum variants to different cryptophyte prey species and concentrations are needed in order to better understand and contextualize these results. Clearly, the nature of this relationship is also sensitive to both prey species and ingestion rate, and suggests that when optimal prey are available, high ingestion rates in $M$. rubrum are a key factor in their ecological success.

Acknowledgements. This research was supported by Academy of Finland research grant 276268 awarded to E.P. and National Science Foundation research grants IOS 1354773 and OCE 1436169 awarded to M.D.J. We thank Drs. Donald $M$. Anderson and Mengmeng Tong for kindly providing the Teleaulax amphioxeia culture GCEP01. We also thank Dr. Holly V. Moeller for helpful comments on the manuscript.

\section{LITERATURE CITED}

Bowers HA, Tengs T, Glasgow HB, Burkholder JM, Rublee PA, Oldach DW (2000) Development of real-time PCR assays for rapid detection of Pfiesteria piscicida and related dinoflagellates. Appl Environ Microbiol 66: 4641-4648

* Deane JA, Strachan IM, Saunders GW, Hill DR, McFadden GI (2002) Cryptomonad evolution: nuclear 18S rDNA phylogeny versus cell morphology and pigmentation. J Phycol 38:1236-1244

Frost BW (1972) Effects of size and concentration of food particles on the feeding behavior of the marine planktonic copepod Calanus pacificus. Limnol Oceanogr 17: 805-815

*Garcia-Cuetos L, Moestrup O, Hansen PJ (2012) Studies on the genus Mesodinium II. Ultrastructural and molecular investigations of five marine species help clarifying the taxonomy. J Eukaryot Microbiol 59:374-400

Gast RJ, Dennett MR, Caron DA (2004) Characterization of protistan assemblages in the Ross Sea, Antarctica, by denaturing gradient gel electrophoresis. Appl Environ Microbiol 70:2028-2037

* Guillard RR, Ryther JH (1962) Studies of marine planktonic diatoms: 1. Cyclotella nana Hustedt, and Detonula confervacia (Cleve) Gran. Can J Microbiol 8:229-239

*Gustafson DE, Stoecker DK, Johnson MD, Van Heukelem WF, Sneider K (2000) Cryptophyte algae are robbed of their organelles by the marine ciliate Mesodinium rubrum. Nature 405:1049-1052

*Hansen PJ, Fenchel T (2006) The bloom-forming ciliate Mesodinium rubrum harbours a single permanent endosymbiont. Mar Biol Res 2:169-177

* Hansen PJ, Moldrup M, Tarangkoon W, Garcia-Cuetos L, Moestrup Ø (2012) Direct evidence for symbiont sequestration in the marine red tide ciliate Mesodinium rubrum. Aquat Microb Ecol 66:63-75

Heinbokel JF (1978) Studies on the functional role of tintinnids in the Southern California Bight. I. Grazing and growth rates in laboratory cultures. Mar Biol 47: 177-189

Herfort L, Peterson TD, McCue LA, Crump BC and others (2011) Myrionecta rubra population genetic diversity and its cryptophyte chloroplast specificity in recurrent red tides in the Columbia River estuary. Aquat Microb Ecol 62:85-97 
Herfort L, Peterson T, Prahl F, McCue L and others (2012) Red waters of Myrionecta rubra are biogeochemical hotspots for the Columbia River Estuary with impacts on primary/secondary productions and nutrient cycles. Estuar Coasts 35:878-891

Hoef Emden K (2008) Molecular phylogeny of phycocyanin containing cryptophytes: evolution of biliproteins and geographical distribution. J Phycol 44:985-993

*Hoef-Emden K, Marin B, Melkonian M (2002) Nuclear and nucleomorph SSU rDNA phylogeny in the Cryptophyta and the evolution of cryptophyte diversity. J Mol Evol 55: 161-179

Jeong HJ, Latz MI (1994) Growth and grazing rates of the heterotrophic dinoflagellates Protoperidinium spp. on red tide dinoflagellates. Mar Ecol Prog Ser 106:173-185

Johnson MD, Stoecker DK (2005) Role of feeding in growth and photophysiology of Myrionecta rubra. Aquat Microb Ecol 39:303-312

Johnson MD, Tengs T, Oldach D, Stoecker DK (2006) Sequestration, performance, and functional control of cryptophyte plastids in the ciliate Myrionecta rubra (Ciliophora). J Phycol 42:1235-1246

Johnson MD, Oldach D, Delwiche CF, Stoecker DK (2007) Retention of transcriptionally active cryptophyte nuclei by the ciliate Myrionecta rubra. Nature 445:426-428

Johnson MD, Stoecker DK, Marshall HG (2013) Seasonal dynamics of Mesodinium rubrum in Chesapeake Bay. J Plankton Res 35:877-893

Johnson MD, Beaudoin DJ, Laza-Martinez A, Dyhrman S and others (2016) The genetic diversity of Mesodinium and associated cryptophytes. Front Microbiol 7:2017

Kim S, Park MG, Moon C, Shin K, Chang M (2007) Seasonal variations in phytoplankton growth and microzooplankton grazing in a temperate coastal embayment, Korea. Estuar Coast Shelf Sci 71:159-169

Kim S, Kang YG, Kim HS, Yih W, Coats DW, Park MG (2008) Growth and grazing responses of the mixotrophic dinoflagellate Dinophysis acuminata as functions of light intensity and prey concentration. Aquat Microb Ecol 51:301-310

Lasek-Nesselquist E, Wisceaver JH, Hackett JD, Johnson MD (2015) Insights into transcriptional changes that accompany organelle sequestration from the stolen nucleus of Mesodinium rubrum. BMC Genomics 16:805

Editorial responsibility: Robert Sanders,

Philadelphia, Pennsylvania, USA
Li A, Stoecker DK, Coats DW (2000) Mixotrophy in Gyrodinium galatheanum (Dinophyceae): grazing responses to light intensity and inorganic nutrients. J Phycol 36: 33-45

Lindholm T (1985) Mesodinium rubrum- a unique photosynthetic ciliate. Adv Aquat Microbiol 3:1-48

*Moeller HV, Johnson MD, Falkowski PG (2011) Photoacclimation in the phototrophic marine ciliate Mesodinium rubrum (Ciliophora). J Phycol 47:324-332

Myung G, Kim HS, Park JS, Park MG, Yih W (2011) Population growth and plastid type of Myrionecta rubra depend on the kinds of available cryptomonad prey. Harmful Algae 10:536-541

Nishitani G, Nagai S, Baba K, Kiyokawa S and others (2010) High-level congruence of Myrionecta rubra prey and Dinophysis species plastid identities as revealed by genetic analyses of isolates from Japanese coastal waters. Appl Environ Microbiol 76:2791-2798

Park JS, Myung G, Kim HS, Cho BC, Yih W (2007) Growth responses of the marine photosynthetic ciliate Myrionecta rubra to different cryptomonad strains. Aquat Microb Ecol 48:83-90

* Peterson TD, Golda RL, Garcia ML, Li B, Maier MA, Needoba JA, Zuber P (2013) Associations between Mesodinium rubrum and cryptophyte algae in the Columbia River estuary. Aquat Microb Ecol 68:117-130

* Rial P, Laza-Martínez A, Reguera B, Raho N, Rodríguez F (2015) Origin of cryptophyte plastids in Dinophysis from Galician waters: results from field and culture experiments. Aquat Microb Ecol 76:163-174

* Riobó P, Reguera B, Franco JM, Rodríguez F (2013) First report of the toxin profile of Dinophysis sacculus Stein from LC-MS analysis of laboratory cultures. Toxicon 76: 221-224

* Smith M, Hansen PJ (2007) Interaction between Mesodinium rubrum and its prey: importance of prey concentration, irradiance and $\mathrm{pH}$. Mar Ecol Prog Ser 338:61-70

*Yih W, Kim HS, Jeong HA, Myung G, Kim YG (2004) Ingestion of cryptophyte cells by the marine photosynthetic ciliate Mesodinium rubrum. Aquat Microb Ecol 36: 165-170

พ Yih W, Kim HS, Myung G, Park JW, Du Yoo Y, Jeong HJ (2013) The red-tide ciliate Mesodinium rubrum in Korean coastal waters. Harmful Algae 30(Suppl 1):S53-S61

Submitted: October 4, 2016; Accepted: November 22, 2016 Proofs received from author(s): January 20, 2017 